ORIGINAL ARTICLE

\title{
Subjective functional assessments and the return to competitive sport after anterior cruciate ligament reconstruction
}

\author{
F W Smith, E A Rosenlund, A K Aune, J A Maclean, S W Hillis
}

See end of article for authors' affiliations ......................

Correspondence to: Mr Smith, Huitfeldtsgate 29, Oslo 0253, Norway; apen@medscape.com

Accepted 8 April 2003

\begin{abstract}
Objectives: To examine (a) return to competitive sport within 12 months of anterior cruciate ligament (ACL) reconstruction, (b) maintenance of competitive participation at follow up, and (c) the relation of the level of sports activity and competitive participation at follow up to subjective functional assessments. Also to address the incidence of continued competitive participation despite notable functional problems with the operated knee at 12 months and follow up.

Methods: All patients were competitive athletes before injury and had undergone ACL reconstruction by the transtibial endoscopic technique with either a bone-patellar tendon-bone or a multiple looped hamstring autograft. Evaluation was carried out a mean of 43 months (range 24-73) after surgery by a postal questionnaire in which the Cincinnati sports activity scale (CSAS) and Cincinnati sports function scales were presented in conjunction with closed questions on change in competitive level and the presence of complaints.

Results: Of 109 selected patients, 77 (71\%) responded. At follow up, 62 of 77 patients (81\%) reported that they had returned to competition within 12 months of surgery. Within the same time frame, 55 of the above 62 patients $(89 \%)$ also claimed to have returned to the level at which they were competing before injury (or higher). At follow up, 30 of the above 55 patients (54\%) reported to still be competing at this high level. Twelve of the above 55 patients $(22 \%)$ also admitted to major problems with the operated knee at that time. The overall incidence of patients competing despite major functional impairment in the operated knee was 13 of $62(21 \%)$ at 12 months and six of $47(13 \%)$ at follow up. Thirty eight patients (49\%) were active in sport at least four times a week at follow up (CSAS level 1), and, using Spearman's rank correlation between CSAS scores and total sports function scores, $r$ was calculated to be 0.44 . Competitive and male patients had higher total sports function scores at follow up than non-competitive $(p=0.005)$ and female $(p=0.02)$ patients respectively.

Conclusions: The reported return to competition at the previous level, both within 12 months and at follow up, was high but as expected considering the standard of treatment, patient selection, and study exclusion criteria. Patients with few functional complaints maintained a high level of sporting activity, even after discontinuing competitive participation.
\end{abstract}

A fter the clinical diagnosis of an anterior cruciate ligament (ACL) rupture in a competitive athlete, reconstructive surgery is indicated primarily by the patient's motivation to return to (a) competition at the previous level or $(b)$ an athletic lifestyle involving functionally challenging activities that were previously impossible because of the ACL deficiency. ${ }^{1-4}$ Although return to competition and maintenance of an athletic lifestyle may be considered to overlap, they should be assessed separately in competitive athletes.

The successful return to competition at the previous level will for most athletes require the near absence of functional limitations. However, some continue to participate in functionally challenging activities, and even compete at a high level despite major functional complaints. Competing with such problems increases the risk of secondary injury, resulting in accelerated deterioration of knee function and progression of osteoarthritis. ${ }^{56}$ No adequate attempts have been made to identify the incidence of such behaviour, which should influence clinicians' consideration of outcomes in terms of sports activity parameters.

Outcome data for heterogeneous samples of athletes receiving standardised treatment are scarce, and studies are needed to identify appropriate outcome variables.
Interestingly, there is a lack of correlation between objective measurements of static stability and subjective assessment of functional limitations after reconstructive ACL surgery.-9 Subjective functional assessments should be presented as outcome principal variables after ACL reconstruction, and the tools for such assessments should be tailored to assess the principal activities of interest to the patients.

Widespread use of tools with a lack of functional variables combined with objective measurements of static stability has introduced concerns about their validity with regard to outcomes in competitive athletes..$^{5} 1111$ The Cincinnati knee rating system is a comprehensive set of tools for assessing functional outcomes after knee ligament surgery and has been adequately tested for reliability, validity, and responsiveness. ${ }^{12}{ }^{13}$ We therefore based our investigation on this system.

The primary objectives of our investigation were to examine the return to and maintenance of competitive participation, and the relation of sports activity and competitive participation to subjective functional assessments at follow up. An additional objective was to address

Abbreviations: $\mathrm{ACL}$, anterior cruciate ligand; CSAS, Cincinnati sports activity scale; CSFS, Cincinnati sports function scales 
Table 1 Inclusion and exclusion criteria

\begin{tabular}{ll}
\hline Inclusion & Exclusion \\
\hline $\begin{array}{l}\text { Endoscopic (transtibial) anterior cruciate ligament } \\
\text { reconstruction using autologous bone-patellar } \\
\text { tendon-bone or hamstring tendon graft }\end{array}$ & $\begin{array}{l}\text { Pre-existing knee pathology or chronic cases } \\
(>12 \text { months from injury/onset of complaint to surgery) }\end{array}$ \\
$\begin{array}{l}\text { Competitive athlete at local, national, or } \\
\text { international/Olympic level (at time of injury) }\end{array}$ & Recreational athletes \\
$\begin{array}{l}\text { Between the ages of } 15(\mathrm{~m}) / 16(\mathrm{f}) \text { and } 30 \text { at } \\
\text { time of surgery }\end{array}$ & $\begin{array}{l}\text { Age }<15(\mathrm{~m}) / 16(\mathrm{f}) \text { or }>30 \\
\text { No intention of competing again at pre-injury level }\end{array}$ \\
\hline
\end{tabular}

the incidence of competitive participation despite appreciable functional problems in the operated knee.

As there was (coincidentally) a fairly even distribution of the sexes in the study sample, sex differences are examined in some key outcome variables.

Although previous studies have looked at return to competition ${ }^{14-17}$ and level of activity ${ }^{81}{ }^{18}$ at follow up, these evaluations were based on heterogeneous samples of athletes subjected to assorted surgical and rehabilitative techniques. Furthermore, previous studies have not specifically investigated the maintenance of competitive participation or focused adequately on the incidence of competitive participation despite appreciable functional complaints in the operated knee.

\section{METHODS \\ Patients}

Patients were retrospectively identified from surgical logbooks dating from January 1994 to February 1998 and selected according to the criteria listed in table 1. Of the 109 patients selected, $77(71 \%)$ responded within two months.

Table 2 summarises the key descriptors of this sample. The sample composition, in terms of the patients' age and sex, illustrated in fig 1 , is similar to that observed in the epidemiological study of ACL injuries in a similar population by Bjordal et al. ${ }^{16}$ Compared with female patients, male patients were older at the time of surgery $(p=0.0005)$, generally had more sporting experience $(p=0.005)$, and were competing at a higher level before injury $(\mathrm{p}=0.002)$. Female patients had surgery significantly longer after injury $(p=0.001)$. Figure 2 shows the distribution of the sample according to the sport played at the time of injury. Five patients had suffered concomitant injuries to the medial collateral ligament, and these lesions were managed nonsurgically by wearing a brace. ${ }^{19}$ Cartilage abnormality or evident concomitant cartilage damage was recorded in four patients, and 16 patients had meniscal lesions. Complete graft failure within the first 12 months occurred in one patient. All basic data, except general sports experience, were collected from the patients' journals and the surgical reports.
Non-responders were not significantly different from the responders in terms of these variables.

\section{Treatment}

All patients had an arthroscopically assisted reconstruction of the ACL, with an ipsilateral autologous bone-patellar tendonbone graft (67 patients) or multiple looped hamstring tendon graft (10 patients). Two experienced surgeons performed all of the procedures and provided standardised follow up. All patients had extensive rehabilitation before the operation, and the rehabilitation after the operation followed the modern, accelerated protocol of Shelbourne and coworkers. $^{20-22}$

\section{Evaluation}

The mean time from surgery to follow up was 43 months (range 24-73). At one month, contactable non-responders were encouraged by telephone to respond. Follow up evaluation was by a postal questionnaire which was completed individually by the patients. The questionnaire was constructed around the Cincinnati sports activity scale (CSAS; fig 3) and Cincinnati sports function scales (CSFS; fig 4). ${ }^{13}$ These scales were presented in conjunction with closed questions on change in level of competitive participation from before the injury, as well as the presence of notable symptoms 12 months after surgery and at follow up. Figure 5 presents the options provided for answering these questions. Table 3 summarises the structure and contents of the questionnaire.

The term "competitive level" is defined by the classification of the competitions in which the athlete was participating, rather than performances at this competitive level.

\section{Statistical analysis}

Interval and ratio scale data were analysed using parametric statistical tools. Differences between groups were assessed using Student's $t$ test. Central tendency and spread in data are indicated by the mean followed by the standard deviation or the confidence interval.

Table 2 Key characteristics of the subjects studied

\begin{tabular}{|c|c|c|c|}
\hline & $\begin{array}{l}\text { Whole sample } \\
\text { (n = 77) }\end{array}$ & $\begin{array}{l}\text { Men } \\
\text { (n = 37) }\end{array}$ & $\begin{array}{l}\text { Women } \\
(n=40)\end{array}$ \\
\hline Age at time of surgery & $21(3.7)$ & $22.4(3.4)$ & $19.3(3.3)$ \\
\hline $\begin{array}{l}\text { Time from injury/onset of symptoms } \\
\text { to surgery (months) }\end{array}$ & $4.6(3.5)$ & $3.4(2.7)$ & $6.1(4.1)$ \\
\hline Time from surgery to follow up (months) & $43(24-73)$ & $41(24-72)$ & $44(24-73)$ \\
\hline $\begin{array}{l}\text { Patients with }>10 \text { years of general sports } \\
\text { experience }\end{array}$ & $48(62.3 \%)$ & $29(78.4 \%)$ & $19(47.5 \%)$ \\
\hline Elite athletes & $59(76.6 \%)$ & $34(91.9 \%)$ & $25(62.5 \%)$ \\
\hline
\end{tabular}

Values are mean (SD), mean (range), or number (\%). Elite refers to competitors in the upper two divisions in football, handball, and basketball, international competitors in alpine skiing and other individual sports, and athletes under the age of 18 attending sports high schools - that is, elite junior athletes. 


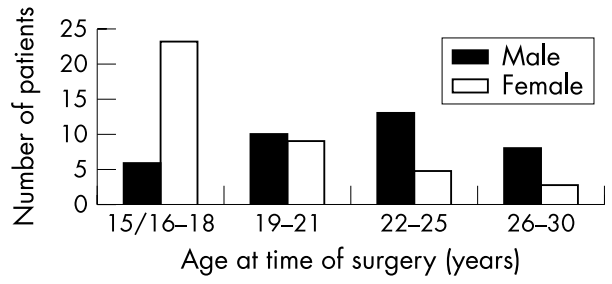

Figure 1 Frequency distribution according to sex and age at the time of surgery.

Ordinal or categorical data were analysed using nonparametric statistical tools; in the assessment of differences between groups in terms of categorical outcomes, the $\chi^{2}$ test was used, and the Mann-Whitney U test was used in the assessment of differences in CSAS and CSFS scores.

Spearman's rank correlation coefficients were used to assess quantitative relations between CSAS and CSFS total scores. Central tendency and spread in data are indicated by the median as well as the mean followed by the standard deviation. Statistical significance was set at $\mathrm{p}<0.05$

\section{RESULTS}

\section{Return to competition}

Table 4 summarises the competitive status of the patients 12 months after surgery and at follow up compared with before the injury. There were no significant differences between male and female patients in terms of return to competition at 12 months, whether the overall return $(\mathrm{p}=$ 0.33 ) or return to the levels achieved before injury (and higher $)(p=0.59)$ were assessed.

\section{Maintenance of competitive participation}

At follow up, the number of competitive patients had decreased significantly from 12 months $(p=0.013)$, as had the proportion of competitive patients competing at the level achieved before injury $(\mathrm{p}<0.001)$. Of the 62 patients that were competitive at 12 months, 46 were still competing at follow up. Of the 43 patients who were competing at their previous level without substantial functional problems at 12 months, 23 (52\%) were still competing at the same level at follow up, seven (16\%) had stopped competing for unrelated reasons, and three $(7 \%)$ had developed functional problems that resulted in their retirement from competitive sport.

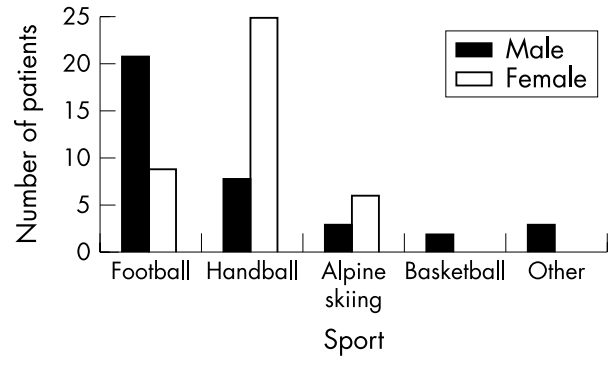

Figure 2 Frequency distribution according to sport at the time of the injury.

\section{Assessment of functional limitation and (general) sports activity at follow up}

Table 5 gives the frequency distribution of scores on the CSAS at follow up. Table 6 gives measures of spread and central tendency in the CSFS. Most patients scored themselves at CSAS levels 1 and 2 (69 of $77(90 \%)$ ), and most of these (38 of $69(55 \%))$ gave themselves the top score at their given level; men did so more often than women (24 of 35 (69\%) $v$ 14 of $34(41 \%) ; p=0.04)$. Table 7 gives Spearman's rank correlation coefficients between sports activity scores and sports function scores at follow up. Competitive patients and male patients had significantly higher overall sports function scores at follow up than did not competitive $(p=0.005)$ and female patients $(\mathrm{p}=0.02)$ respectively. Patients who were not competitive at follow up and reported having major impairment had significantly lower overall sports function scores (at follow up) than did those who were not competitive for other (unrelated) reasons $(p<0.0001)$. The reduction, from 12 months to follow up, in the proportion of patients with problems with the operated knee who were competing at their previous level was not significant $(\mathrm{p}=$ $0.43)$.

\section{Incidence of continued competitive participation despite functional impairment of the operated knee} Table 4 gives these results.

The significance of the increased proportion of patients that were not competitive because of functional impairment from 12 months to follow up is not possible to assess in a meaningful way because of the small numbers.

$\begin{aligned} \text { Points } & \text { Activity } \\ & \text { Level } 1 \text { (participates 4-7 days/week) } \\ 100 & \text { Jumping, hard pivoting, cutting (basketball, volleyball, football, soccer, gymnastics) } \\ 95 & \text { Running, twisting, turning (racquet sports, baseball, hockey, skiing, wrestling) } \\ 90 & \text { No running, twisting, jumping (cycling, swimming) } \\ & \text { Level } 2 \text { (participates 1-3 days/week) } \\ 85 & \text { Jumping, hard pivoting, cutting (basketball, volleyball, football, soccer, gymnastics) } \\ 80 & \text { Running, twisting, turning (racquet sports, baseball, hockey, skiing, wrestling) } \\ 75 & \text { No running, twisting, jumping (cycling, swimming) } \\ & \text { Level 3 (participates 1-3 times/month) } \\ 65 & \text { Jumping, hard pivoting, cutting (basketball, volleyball, football, soccer, gymnastics) } \\ 60 & \text { Running, twisting, turning (racquet sports, baseball, hockey, skiing, wrestling) } \\ 55 & \text { No running, twisting, jumping (cycling, swimming) } \\ & \text { Level } 4 \text { (no sports) } \\ 40 & \text { Activities of daily living with no problems } \\ 20 & \text { Activities of daily living with moderate problems } \\ 0 & \text { Activities of daily living with severe problems }\end{aligned}$

Figure 3 Cincinnati sports activity scale. Reproduced, with permission, from Barber-Westin et al. ${ }^{13}$ The scale consists of 12 scores distributed across four levels. The three scores at each level correspond to three intensities of force to which the lower extremities are subjected, and the level indicates the frequency of participation in that type of activity. 


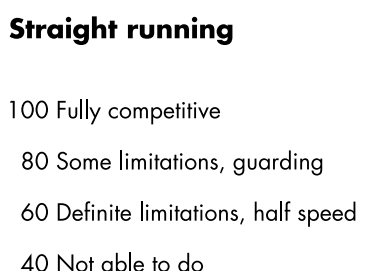

\section{Jumping/landing on affected leg}

100 Fully competitive

80 Some limitations, guarding

60 Definite limitations, half speed

40 Not able to do

\section{Hard twists/cuts/pivots}

100 Fully competitive

80 Some limitations, guarding

60 Definite limitations, half speed

40 Not able to do

Figure 4 Cincinnati sports function scales. Reproduced, with permission, from Barber-Westin et al..$^{13}$

\section{DISCUSSION}

The apparent lack of outcome data with appropriate outcome measures for competitive athletes prompted this investigation. Little emphasis has previously been placed on the immediate return to and maintenance of competitive participation, although these are important objectives for competitive athletes. In addition, investigators have typically presented results from samples that included chronic cases (surgery more than 12 months after injury), older patients (>35 years), and patients with pre-existing knee pathology.

\section{Return to competition}

The high rate of return to competition 12 months after surgery was expected, given the study inclusion criteria, the accelerated rehabilitation schedule, and the high motivation of the patients to achieve this objective. The latter is also reflected by the high proportion who managed to return to the competitive level achieved before injury. Although sex differences for return to competition within 12 months were not significant, the somewhat higher results for the male patients were in accordance with experience and were expected given the findings of Bjordal et al, ${ }^{16}$ who assessed outcomes in a similar population.

The sex differences can largely be attributed to the lower age of the female patients and the lower proportion of elite female athletes in the sample. For younger athletes, unresolved educational and/or occupational issues are more likely to present attractive "unrelated reasons" for discontinuing competitive participation.

Considering the rehabilitation schedule and the high motivation of the patients, a return to competitive sport at the previous level within 12 months is a realistic objective,

\section{Higher}

None or insignificant problems

Moderate/significant problems

\section{Not changed}

None or insignificant problems

Moderate/significant problems

Lower

None or insignificant problems

Moderate/significant problems

Stopped

Moderate/significant problems

Reasons not related to my knee (including fear of re-injuryl

Figure 5 Question on change in level of competitive participation compared with before the injury. and these results support this. Their motivation was discussed with patients before surgery, and the lack of such motivation resulted in exclusion from the study.

It may be argued that the athletes' accuracy of recall of their status at 12 months is questionable. However, with an accelerated rehabilitation schedule, this is the time frame within which most competitive athletes will aim/expect to achieve a satisfactory return to competitive sports after an uncomplicated ACL reconstruction.

\section{Maintenance of competitive participation}

We considered maintenance of competitive status to be important. It is worth emphasising that two thirds of patients who discontinued their competitive career did so for reasons other than the injury. The lower maintenance for patients who managed the initial return to competition at their previous level was expected, given the greater demands (in general) of maintaining a competitive career at a high level and because any functional limitations would be magnified on return to the previous competitive level, compared with a lower competitive level (regardless of the previous level).

\section{Incidence of patients continuing competitive participation despite functional impairment}

The incidence was somewhat lower than expected from experience. The higher incidence reported 12 months after surgery than at follow up is probably part of a natural pattern of trial of functional capacity, but the small sample size makes this observation difficult to assess.

Notably, few of the patients who reported competing despite problems at 12 months were similarly competitive at follow up. The return to competitive status should be considered in the light of the incidence of such behaviour, although its significance, in particular over short periods, is largely unknown. One may hypothesise that the typical behaviour involves accepting some degree of discomfort and pain during the initial return to competitive activity; later the condition will either improve, allowing the level of competitive participation to be maintained, or deteriorate, forcing the patient to adjust his/her competitive participation, or even retire from competitive participation altogether.

Table 3 Questionnaire structure and contents

\begin{tabular}{|c|c|}
\hline $\begin{array}{l}\text { Question } \\
\text { number }\end{array}$ & Question content \\
\hline 1 & General sports experience before the injury (years) \\
\hline 2 & Pre-injury competitive level (local, national, or international) \\
\hline 3 & $\begin{array}{l}\text { Change in competitive level; pre-injury versus } 12 \text { months after } \\
\text { surgery }\end{array}$ \\
\hline 4 & $\begin{array}{l}\text { Change in competitive level; pre-injury versus present follow } \\
\text { up }\end{array}$ \\
\hline 5 & Cincinnati sports activity scale (general sports activity) \\
\hline $6-8$ & Cincinnati sports function scales \\
\hline 9 & Regarding subsequent surgical intervention in the same knee \\
\hline
\end{tabular}


Table 4 Competitive status 12 months after surgery and at follow up

\begin{tabular}{|c|c|c|c|c|c|c|}
\hline & \multicolumn{3}{|c|}{12 months after surgery } & \multicolumn{3}{|c|}{ Follow up } \\
\hline & $\begin{array}{l}\text { Male } \\
(n=37)\end{array}$ & $\begin{array}{l}\text { Female } \\
(n=40)\end{array}$ & $\begin{array}{l}\text { Sample } \\
(n=77)\end{array}$ & $\begin{array}{l}\text { Male } \\
(n=37)\end{array}$ & $\begin{array}{l}\text { Female } \\
(n=40)\end{array}$ & $\begin{array}{l}\text { Sample } \\
(n=77)\end{array}$ \\
\hline \multicolumn{7}{|l|}{ Competitive } \\
\hline All & $32(86)$ & $30(75)$ & $62(81)$ & $28(76)$ & $19(47.5)$ & $47(61)$ \\
\hline No problems & $25(78)$ & $24(80)$ & $49(79)$ & $24(86)$ & $17(89.5)$ & $41(87)$ \\
\hline Problems & $7(22)$ & $6(20)$ & $13(21)$ & $4(14)$ & $2(10.5)$ & $6(13)$ \\
\hline \multicolumn{7}{|l|}{ Previous level or higher } \\
\hline All & $28(76)$ & $27(67.5)$ & $55(71)$ & $18(49)$ & $14(35)$ & $32(42)$ \\
\hline No problems & $21(75)$ & $22(81.5)$ & $43(78)$ & $16(89)$ & $12(86)$ & $28(87.5)$ \\
\hline Problems & $7(25)$ & $5(18.5)$ & $12(22)$ & $2(11)$ & $2(14)$ & $4(12.5)$ \\
\hline \multicolumn{7}{|l|}{ Lower level } \\
\hline All & $4(11)$ & $3(7.5)$ & $7(9)$ & $10(27)$ & $5(12.5)$ & $15(19)$ \\
\hline No problems & $4(100)$ & $2(67)$ & $6(86)$ & $8(80)$ & $5(100)$ & $13(87)$ \\
\hline Problems & $0(0)$ & $1(33)$ & 1 (14) & $2(20)$ & $0(0)$ & $2(13)$ \\
\hline \multicolumn{7}{|l|}{ Non-competitive } \\
\hline All & $5(13.5)$ & $10(25)$ & $15(19.5)$ & $9(24)$ & $21(52.5)$ & $30(39)$ \\
\hline For other reasons & $3(60)$ & $4(40)$ & $7(47)$ & $7(78)$ & $13(62)$ & $20(67)$ \\
\hline $\begin{array}{l}\text { Because of functional } \\
\text { impairment }\end{array}$ & $2(40)$ & $6(60)$ & $8(53)$ & $2(22)$ & $8(38)$ & 10 (33) \\
\hline
\end{tabular}

Table 5 Distribution of CSAS scores at follow up

\begin{tabular}{|c|c|c|c|c|c|c|c|}
\hline \multirow[b]{2}{*}{ Level } & \multirow[b]{2}{*}{ Score } & \multicolumn{2}{|c|}{ Male $(n=37)$} & \multicolumn{2}{|c|}{ Female $(n=40)$} & \multicolumn{2}{|c|}{ All $(n=77)$} \\
\hline & & No & $\%$ & No & $\%$ & No & $\%$ \\
\hline \multirow[t]{3}{*}{1} & 100 & 15 & 40.5 & 7 & $\begin{array}{l}17.5 \\
17.5\end{array}$ & 22 & 28.6 \\
\hline & 95 & 7 & 18.9 & 7 & 17.5 & 14 & 18.2 \\
\hline & 90 & 1 & 2.7 & 1 & 2.5 & 2 & 2.6 \\
\hline \multirow[t]{3}{*}{2} & 85 & 9 & 24.3 & 7 & 17.5 & 16 & 20.8 \\
\hline & 80 & 1 & 2.7 & 8 & 20 & 9 & 11.7 \\
\hline & 75 & 2 & 5.4 & 4 & 10 & 6 & 7.8 \\
\hline \multirow[t]{3}{*}{3} & 65 & 0 & 0 & 1 & 2.5 & 1 & 1.3 \\
\hline & 60 & 1 & 2.7 & 1 & 2.5 & 2 & 2.6 \\
\hline & 55 & 0 & 0 & 0 & 0 & 0 & 0 \\
\hline \multirow[t]{3}{*}{4} & 40 & 1 & 2.7 & 2 & 5 & 3 & 3.9 \\
\hline & 20 & 0 & 0 & 2 & 5 & 2 & 2.6 \\
\hline & 0 & 0 & 0 & 0 & 0 & 0 & 0 \\
\hline
\end{tabular}

Table 6 Spread and central tendency of Cincinnati sports function scales scores at follow up

\begin{tabular}{llll}
\hline Patient category & & Median & SD \\
\hline Sample $(n=77)$ & Total score & 280 & 34.1 \\
& Straight running & 100 & 12 \\
& Twisting/turning & 100 & 13.2 \\
& Jumping/landing & 80 & 13.5 \\
Male $(n=37)$ & Total score & 300 & 26.9 \\
& Straight running & 100 & 9.24 \\
& Twisting/turning & 100 & 10.6 \\
& Jumping landing & 100 & 12.1 \\
Female $(n=40)$ & & & 37.9 \\
& Total score & 280 & 13.6 \\
& Straight running & 100 & 14.5 \\
Competitive $(n=47)$ & Twisting/turning & 80 & 14.5 \\
Non-competitive & Jumping landing & 80 & 21.6 \\
For other reasons $(n=20)$ & Total score & 280 & \\
Because of functional impairment $(n=10)$ & & & 25 \\
\hline
\end{tabular}


Table 7 Spearman's rank correlation coefficients between Cincinnati sports activity scale and Cincinnati sports function scales total scores at follow up

\begin{tabular}{lll}
\hline & $r$ Value & $p$ Value \\
\hline Sports (total score) & 0.44 & $<0.001$ \\
Straight running & 0.45 & $<0.001$ \\
Twisting/turning & 0.47 & $<0.001$ \\
Jumping/landing & 0.33 & 0.004 \\
\hline
\end{tabular}

Because of the small sample size, the significance of the relative reduction in the incidence from 12 months to follow up was difficult to assess. However, one may hypothesise that the typical behaviour involves accepting some degree of discomfort and pain during the initial return to competitive activity; later the condition will either improve, allowing the level of competitive participation to be maintained, or deteriorate, forcing the patient to adjust his/her competitive participation, or to choose to retire from competitive participation (in that particular sport) altogether.

Functional limitations and sports activity at follow up Like other studies using similar surgical techniques and rehabilitative approach, ${ }^{1622} 23$ the great majority of patients, by reporting very few functional limitations, perceived the outcome as satisfactory. In common with the study by Wiger et $a l,{ }^{17}$ the high activity levels maintained by patients at follow up supported the validity of their subjective assessments of their functional limitations.

Patients may reduce their activity levels for many reasons other than functional impairment, reducing the relation between actual sports activity and the subjective rating of functional limitation. It was encouraging that patients who had discontinued competitive participation for reasons other than problems with the operated knee reported maintaining a highly athletic lifestyle, both in terms of the type of activity and frequency at follow up, indicating that surgery had in fact been appropriately performed in these patients.

Patients with major knee problems at follow up had a lower CSAS score mode, reflecting the reduced intensity of sports activity compared with that of those without such problems, which is logical.

We have not focused on the changes in sports activity and degree of functional limitation relative to the time from surgery to follow up, principally because of the small and somewhat unevenly distributed sample. The progressive changes in functional and sports activity variables for patients with major functional impairment, or with concomitant lesions at the time of surgery, would require a substantially longer follow up period and prospective study design.

The principal limitation of our study was the small sample size, which limited the scope for data analysis. Appropriate selection of patients, continued use of validated tools for assessment, and, preferably, data collection in a prospective fashion should reduce the ambiguity of results in future studies. Although the satisfactory outcomes of surgery in this population were as expected, appropriate outcome measures should be audited and discussed in a factual context rather than inferred from experience.

\section{Authors' affiliations}

E A Rosenlund, A K Aune, Volvat Medical Centre, Oslo, Norway F W Smith, J A MacLean, S W Hillis, Department of Medicine and Therapeutics, University of Glasgow, Glasgow, Scotland, UK

\section{REFERENCES}

1 Noyes FR, Basset RW, Grood ES, et al. Arthroscopy in acute traumatic hemarthrosis of the knee: incidence of anterior cruciate ligament tears and other injuries. J Bone Joint Surg [Am] 1980;62:687-95.

2 Noyes FR, Mooar PA, Matthews DS, et al. The symptomatic anterior cruciate ligament deficient knee. Part 1: the long-term functional disability in athletically active individuals. J Bone Joint Surg [Am] 1983;65:154-62.

3 Zarins B, Adams M. Medical Progress: knee injuries in sports. N Engl J Med 1988;318:950-61.

4 Scavenius M, Bak K, Hansen S, et al. Isolated total ruptures of the anterior cruciate ligament: a clinical study with long-term follow-up of 7 years. Scand J Med Sci Sports 1999;9:114-19.

5 Barber Westin SD, Noyes FR. Assessment of sports participation levels following knee injuries. Sports Med 1999;28:1-10.

6 Ferretti A, Conteduca F, De Carli A, et al. Osteoarthritis of the knee after ACL reconstruction. Int Orthop 1991;15:367-71.

7 Muneta T, Sekiya I, Ogiuchi T, et al. Objective factors affecting overall subjective evaluation of recovery after anterior cruciate ligament reconstruction. Scand J Med Sci Sports 1998;8:283-9.

8 Sernert N, Kartus J, Kohler K, et al. Analysis of subjective, objective and functional examination tests after anterior cruciate ligament reconstruction. A follow-up of 527 patients. Knee Surg Sports Traumatol Arthrosc 1999;7:160-5

9 Wilk KE, Romaniello WT, Socia SM, et al. The relationship between subjective knee scores, isokinetic testing, and functional testing in the $\mathrm{ACL}$ reconstructed knee. J Orthop Sports Phys Ther 1994;20:60-73.

10 Sgaglione NA, Del Pizzo W, Fox JM, et al. Critical analysis of knee ligament rating systems. Am J Sports Med 1995;23:660-7.

11 Bengtsson J, Möllborg J, Werner S. A study for testing the sensitivity and reliability of the Lysholm knee scoring scale. Knee Surg Sport Traumatol Arthrosc 1996;4:27-31.

12 Risberg MA, Holm I, Steen $\mathrm{H}$, et al. Sensitivity to changes over time for the IKDC form, the Lysholm score, and the Cincinnati knee score. A prospective study of $120 \mathrm{ACL}$ reconstructed patients with a 2-year follow-up. Knee Surg Sports Traumatol Arthrosc 1999;7:152-9.

13 Barber-Westin SD, Noyes FR, McCloskey JW. Rigorous statistical reliability, validity, and responsiveness testing of the Cincinnati Knee Rating System in 350 subjects with uninjured, injured, or anterior cruciate ligamentreconstructed knees. Am J Sports Med 1999;27:402-16.

14 Engström B, Forssblad $M$, Johansson $C$, et al. Does a major knee injury definitely sideline an elite soccer player? Am J Sport Med 1990;18:101-5.

15 Roos H, Ornell M, Gärdsell P, et al. Soccer after anterior cruciate ligament injury-an incompatible combination? A national survey of incidence and risk factors and a 7 year follow-up of 310 players. Acta Orthop Scand 1995;66:107-12

16 Bjordal JM, Arnøy F, Hannestad B, et al. Epidemiology of anterior cruciate ligament injuries in soccer. Am J Sports Med 1997;25:341-5.

17 Wiger $\mathbf{P}$, Brandsson S, Kartus J, et al. A comparison of results after anterior cruciate ligament reconstruction in female and male competitive athletes: a two- to five-year follow-up of 429 patients. Scand J Med Sci Sports 1999;9:290-5.

18 Karlsson J, Kartus J, Magnusson L, et al. Subacute versus delayed reconstruction of the anterior cruciate ligament in the competitive athlete. Knee Surg Sports Traumatol Arthrosc 1999;7:146-51.

19 Noyes FR, Barber-Westin SD. The treatment of combined ruptures of the anterior cruciate and medial ligaments of the knee. Am J Sports Med 1995;23:380-9.

20 Shelbourne KD, Nitz P. Accelerated rehabilitation after anterior cruciate ligament reconstruction. Am J Sports Med 1990;18:292-9.

21 Shelbourne KD, Wilckens HJ, Mollabashy A, et al. Arthrofibrosis in acute anterior cruciate ligament reconstruction. The effect of timing of reconstruction and rehabilitation. Am J Sports Med 1991;19:332-6.

22 Shelbourne KD, Gray T. Anterior Cruciate ligament reconstruction with autologous patellartendon graft followed by accelerated rehabilitation. A twoto nine-year follow up. Am J Sports Med 1997;25:786-95.

23 Karlsson J, Kartus J, Brandsson S, et al. Comparison of arthroscopic oneincision and two incision techniques for reconstruction of the anterior cruciate ligament. Scand J Med Sci Sports 1999;9:233-8. 